\title{
The SCIP Database under Directive (EU) 2018/851
}

\section{Do ECHA's Detailed Information Requirements Cross the Legal Boundaries?}

\author{
Tim Becker*
}

With the forthcoming database on substances of concern in articles as such or in complex objects (products) (hereafter SCIP database) ${ }^{1}$ the EU's co-legislators have introduced a highly ambitious project for all parties involved at the EU, national and global level. The requirement is set out in Article 9(1)(i) and (2) of Directive 2008/98/EC on waste, as revised by Directive (EU) 2018/851 of the European Parliament and of the Council of 30 May 2018 (hereafter Waste Framework Directive, WFD or revised WFD). At its recent SCIP workshop $2019^{2}$ the European Chemicals Agency (ECHA) presented and discussed with numerous participants from industry, authorities and NGOs the current state of play of the database, which ECHA should establish by 5 January 2020. In particular, the scope of ECHA's detailed information requirements for SCIP notifications was criticized from the industry side for exceeding legal boundaries, while others argued in support of the ECHA plans. This question is of high practical relevance. Essentially, the issue at stake is whether industry can rely on existing systems and data already communicated under Article 33(1) of Regulation (EC) No 1907/2006 (REACH), or whether additional data has to be collected from often long and complex global supply chains for the purpose of SCIP notifications, which are due as from 5 January 2021. Against this background, the present article aims to take a closer look at the legal background for the new SCIP provisions and discuss ECHA's detailed information requirements from a legal point of view, based on the underlying rationale of the European Commission (EC). We will see that the role of recitals in EU law for the interpretation of enacting terms is one of the key legal issues raised in this context.

\section{Legal Background}

The discussion of the legal background for SCIP notification and database shall start with the enacting terms in WFD Article 9. Thereafter the rationale as given in recital 38 of Directive (EU) 2018/851 will be

DOI: $10.21552 / \mathrm{icrl} / 2019 / 4 / 4$

* Tim Becker is Senior Legal Advisor at REACHLaw Ltd. in Espoo, Finland. He is a specialist on EU chemicals regulatory issues. Reference for more information: <https://www.reachlaw.fi/person/ tim-becker>.

1 See $<$ https://echa.europa.eu/scip-database $>$ accessed 2 December 2019).

2 See $<$ https://echa.europa.eu/-/scip-workshop-12-november-2019> accessed 2 December 2019. detailed (2.), followed by a brief look at the genesis of SCIP (and REACH Article 33) requirements (3.). The discussion of the required national transposition of Directive (EU) 2018/851 will conclude this Chapter (4.).

\section{Enacting Terms}

SCIP provisions are introduced in Article 9 of the revised WFD titled 'prevention of waste'. As regards the notification, WFD Art. 9(1) foresees that 'Member States shall take measures to prevent waste generation. Those measures shall, at least: [...] (i) promote the reduction of the content of hazardous sub- 
stances in materials and products, without prejudice to harmonised legal requirements concerning those materials and products laid down at Union level, and ensure that any supplier of an article as defined in point 33 of Article 3 of Regulation (EC) No 1907/2006 of the European Parliament and of the Council provides the information pursuant to Article 33(1) of that Regulation to the European Chemicals Agency as from 5 January 2021; [...]". Further to this, WFD Art. 9(2) stipulates that "[the]he European Chemicals Agency shall establish a database for the data to be submitted to it pursuant to point (i) of paragraph 1 by 5 January 2020 and maintain it. The European Chemicals Agency shall provide access to that database to waste treatment operators. It shall also provide access to that database to consumers upon request."

Thus, WFD Art. 9(1)(i) and (2) link the SCIP notification duty and database to the communication duty for EU article suppliers under REACH Article 33(1), which requires that any supplier of an article containing a substance of very high concern (SVHC) included in the REACH Candidate List ${ }^{3}$ in a concentration above $0.1 \%$ weight by weight $(\mathrm{w} / \mathrm{w})$ provides the recipient of the article 'with sufficient information, available to the supplier, to allow safe use of the article including, as a minimum, the name of that substance."

In essence, the REACH communication obligation in the supply chain for substances in articles is thus complemented by a notification obligation to ECHA for its forthcoming SCIP database. REACH Art. 7(2) already has an existing 'substance-centric' duty for producers and importers of articles containing Candidate List substances to notify ECHA, but only if they are present in articles above one tonne per legal entity per year. The main objective of the extension, as apparent from WFD Art. 9(2) $2^{\text {nd }}$ sentence, is to ensure that waste treatment operators also have access to this information. This is typically not the case under REACH Art. 33(1), because it only applies visà-vis the 'recipient of the article", i.e. 'an industrial or professional user, or a distributor, being supplied with an article but does not include consumers' (REACH Art. 3(35)); however 'waste' as defined in WFD is not an 'article' within the meaning of REACH (REACH Art. 2(2)).

In addition, consumers shall have access to the SCIP database upon request, thus extending their existing 'right to know' under REACH Art. 33(2).

\section{Rationale: Recital 38}

Recital 38 of Directive (EU) 2018/851 further addresses the rationale for the SCIP provisions, as follows:

'When products, materials and substances become waste, the presence of hazardous substances may render that waste unsuitable for recycling or the production of secondary raw materials of high quality. Therefore, in line with the 7 th Environment Action Programme, which calls for the development of non-toxic material cycles, it is necessary to promote measures to reduce the content of hazardous substances in materials and products, including recycled materials, and to ensure that sufficient information about the presence of hazardous substances and especially substances of very high concern is communicated throughout the whole life cycle of products and materials. In order to achieve those objectives, it is necessary to improve the coherence among the law of the Union on waste, on chemicals and on products and to provide a role for the European Chemicals Agency to ensure that the information about the presence of substances of very high concern is available throughout the whole life cycle of products and materials, including at the waste stage."

Recital 38 can be broken down into three parts. First, the problem is raised, i.e. waste unsuitable for recycling etc. due to the presence of hazardous substances ( $1^{\text {st }}$ sentence). Second, the objectives are identified, i.e. (1) the elimination of hazardous substances for the development of non-toxic material cycles and (2) the communication of sufficient information about the presence of hazardous substances and especially SVHCs throughout the whole life cycle of products and materials ( $2^{\text {nd }}$ sentence). Finally, the means to achieve these objectives are introduced, i.e. (1) to improve the coherence among the law of the Union on waste, on chemicals and on products ${ }^{4}$ and (2) to provide a role for ECHA to ensure that the information about the presence of SVHCs is available throughout the whole life cycle of products and materials, including at the waste stage ( $3^{\text {rd }}$ sentence). The first means (coherence) is enacted in WFD Art.

3 For details see $<$ https://echa.europa.eu/candidate-list-table $>$ accessed 2 December 2019. Other substances of concern are currently not covered by SCIP.

4 See also recital 4 of Directive (EU) 2018/851: 'The coherence between Directive 2008/98/EC and related Union legislative acts such [...] Regulation (EC) No 1907/2006 of the European Parliament and of the Council needs to be ensured." 
9(1)(i) and the second means (provide a role for ECHA) in WFD Art. 9(2).

\section{Legal Basis and Genesis}

Directive (EU) 2018/851 makes reference to Article 192(1) of the Treaty on the Functioning of the European Union (TFEU), which tasks the European Parliament and the Council to decide what action is to be taken by the Union in order to achieve the objectives referred in TFEU Article 191, i.e. the Union policy on the environment. The Directive is part of the implementation of the EU's action plan for the Circular Economy (CE) adopted in $2015 .^{5}$

It is interesting to note that neither the SCIP provisions nor the related REACH Article 33 were part of the underlying EC initial proposals. Both were added only during the legislative process of the European Parliament and the Council. The SCIP requirements in particular form an integral part of their agreement made in December 2017 on the review of EU waste legislation.

5 EC, 'Closing the Loop - An EU Action Plan for the Circular Economy' 2 December 2015, available at <https://eur-lex.europa .eu/legal-content/EN/TXT/?uri=CELEX\%3A52015DC0614> accessed 2 December 2019.

6 Interinstitutional Agreement between the European Parliament, the Council of the European Union and the European Commission on Better Law-Making, 13 April 2016, available at <https:/ eur-lex.europa.eu/legal-content/EN/TXT/?uri=CELEX

\%3A32016Q0512\%2801\%29< accessed 2 December 2019.

7 Subject to some possible exceptions, such as Member State interests of defence, essential interests of security (see EC, Nonpaper on the implementation of articles 9(1)(i) and 9(2) of the revised Waste Framework Directive 2008/98/EC, Ref Ares(2019) 3936110, 20 June 2019, 3, available at <https://circabc. europa .eu/w/browse/8a073cb6-03cb-4665-a866-4a17b17a6f60> accessed 14 November 2019, and for equipment designed to be sent into space and related means of transport (see ASD-Eurospace, Space Industry Position regarding Article 9 of the revised Waste Framework Directive 2008/98/EC, 9 September 2019, available at <https://eurospace.org/wp-content/uploads/2019/09/ wfd-position-eurospace-09092019-signed.pdf > accessed 14 November 2019.

8 International Uniform Chemical Information Database.

9 See <https://iuclid6.echa.europa.eu/view-article/-/journal _content/title/iuclid-6-4-is-available> accessed 2 December 2019.

10 See ECHA, 'Update on the SCIP database of articles containing Candidate List substances, Doc. CA/73/2019 of 22 October 2019 for the 32nd Meeting of Competent Authorities for REACH and CLP on 6-7 November 2019' available at $<$ https://circabc.europa .eu/w/browse/8a073cb6-03cb-4665-a866-4a17b17a6f60> accessed 15 November 2019.

11 ECHA, 'Detailed information requirements for the SCIP database' (September 2019) available at < https://echa.europa.eu/ documents/10162/28213971/scip_information_requirements_en .pdf $>$ accessed 15 November 2019.

$12 \mathrm{EC}$, (n 7). The non-paper was prepared by the EC's DG Environment as the responsible Commission services.
A prior impact assessment before the adoption of the revised WFD, that would address feasibility and costs for industry and usefulness of the SCIP database for waste operators, was not done. Impact assessment and stakeholder consultation are recognized as key 'tools for Better Law-Making' by the European Parliament, the Council and the Commission. $^{6}$

\section{Member State Transposition}

Unlike REACH, which as a 'regulation' is directly applicable in all Member States (TFEU Art. 288(2)), Directive (EU) 2018/851 including its SCIP provisions has to be transposed by the Member States. Transposition is due by 5 July 2020 (Art. 2(1) of Directive (EU) $2018 / 851)$. A directive is binding, as to the result to be achieved, upon each Member State to which it is addressed, but shall leave to the national authorities the choice of form and methods (TFEU Art. 288(3)).

With regard to SCIP notification, WFD Article 9(1)(i) does not seem to leave much ${ }^{7}$ flexibility for Member States, given that WFD Article 9(2) requires ECHA to establish the SCIP database already by 5 January 2020, i.e. well before national transposition is due. This could create a problematic fait accompli for the Member States. ECHA has already published the first IUCLID ${ }^{8}$ tool version compatible with SCIP at the end of October 2019. ${ }^{9}$

Meanwhile, ECHA stresses the need for a harmonised transposition of WFD Art. 9, and has even recommended the following text as 'inspiration' for Member States, thus expanding on WFD Art. 9(1)(i): ${ }^{10}$

'Any supplier of an article as defined in point 33 of Article 3 of Regulation (EC) No 1907/2006 of the European Parliament and of the Council provides the information pursuant to Article 33(1) of that Regulation to the European Chemicals Agency as from 5 January 2021 using the format(s) and submission tool(s) provided by this Agency for that purpose.'

\section{Outline of ECHA's Plans}

ECHA's 'Detailed information requirements for the SCIP database ${ }^{11}$ published on 9 September 2019 are based on the EC's 'Non-paper on the implementation of articles 9(1)(i) and 9(2) of the revised Waste Framework Directive 2008/98/EC' of 20 June $2019 .{ }^{12}$ These 
requirements are summarised in Section 1 below, followed by their justification (Section 2).

\section{SCIP Information Requirements}

In its 'non-paper', the EC has concluded that the minimum available information which the supplier has to communicate to ECHA under WFD Art. 9 consist of three elements: ${ }^{13}$

(i) information relevant to the identification of the article;

(ii) name, concentration range and location of the SVHC;

(iii) where information in point (ii) is not sufficient, other information on the safe use of the article, in particular available information that is relevant to ensure proper management of the article as waste. These three elements - article identification, SVHC in the article ('concern element') and safe use information - have been further refined by ECHA. ${ }^{14}$ The article identification shall include as mandatory data ${ }^{15}$ the name, a numerical or alphanumerical identifier and identification of its type (so-called 'primary article identifier'), the article category using a TARIC/CN code $^{16}$ and answering the question whether the article is produced or assembled in the EU. For the concern element, i.e. the information on the Candidate List substance(s) present in an article as such in a concentration above $0.1 \% \mathrm{w} / \mathrm{w}$, the duty holder has to select the Candidate List version used, concentration range, material category of the article or mixture category containing the SVHC.

Importantly, most articles are not supplied as such (simple articles on their own, e.g. a screw), but as part of assemblies of articles, which may add up to very or super complex objects containing thousands to millions of component articles (e.g. think of electronics, phones, laptops, cars or an aircraft). In these cases, the article identification requirements are seen by ECHA as a 'recurrent block' for complex object components ('linked articles'), which are to be fulfilled until the concern element is identified. ${ }^{17}$ The number of occurrences ('units') of the linked article(s) in the complex object is also required..$^{18}$

For very complex objects with many sub-assembly levels this raises the question how their hierarchy is to be reported. At the SCIP workshop on 12 November 2019 ECHA was not able to provide a clear answer, but pointed out that 'the format is intentional- ly flexible' and 'a lot of room for discretion lies with the duty holders', ${ }^{19}$ who should make sure that the level of reporting is still meaningful to the users. ${ }^{20}$

\section{Justification}

The EC justifies the extensive scope of SCIP information requirements with view to the enacting terms, REACH Article 33(1) and recital 38, which were already discussed in Section I.1. and I.2. The EC concludes: ${ }^{21}$ 'Article 9(2) of the WFD provides that information pursuant to Article 33(1) has to be included in a database to be used primarily by waste treatment operators. The information made available to those operators via the database has to be useful for the waste treatment phase of the article's lifecycle and enable the identification and effective treatment of waste containing SVHC, as laid down in recital 38 of the WFD elaborating the objective of the database:[quote of recital 38].'

ECHA essentially relies on this EC justification, ${ }^{22}$ and adds further to it. ECHA highlights that it 'is designing the SCIP database with the dual aim to gather the information that is necessary for achieving the objectives of WFD Art. 9(2), and that this information will be structured and searchable, in order to enable optimised access and use primarily by waste operators and consumers, as well as by actors in the supply chain, NGOs and authorities. ${ }^{23}$ For waste op-

\footnotetext{
13 See EC, (n 7) 2.

14 See ECHA, (n 11) 5 et seqq.

15 In addition, ECHA also foresees the possibility to provide other information on a voluntary basis, such as brand, model and type of a product, or disassembling instructions.

16 The integrated Tariff of the European Union - TARIC - list, based on the Combined Nomenclature $(\mathrm{CN})$ description and code [Annex I to Council Regulation (EEC) No 2658/87].

17 See ECHA, (n 11) 7 .

18 See ECHA, (n 11) 9

19 See ECHA/Uotila, 'IT implementation of the SCIP database' presentation at ECHA SCIP workshop on 12 November 2019 in Helsinki, available at <https://echa.europa.eu/documents/10162/ 28534369/3_scip_en.pdf/539e6831-9279-69b2-e8df -5aafcc41f1e7> accessed 15 November 2019.

20 See ECHA / de Bruijn, 'Wrap-up and conclusions' presentation at ECHA SCIP workshop on 12 November 2019 in Helsinki, available at <https://echa.europa.eu/documents/10162/28534369/9 _scip_en.pdf/77f6f404-bbf2-9d86-276d-0afc9aa0fc85> accessed 19 November 2019.

21 See EC, (n 7) 1

22 See ECHA, (n 11) 2.

23 See ECHA, (n 11) 2.
} 
erators, the database would serve to provide available information to drive waste stream decisions, support compliant re-use and increase recycled materials. For consumers and interested parties, the database would help empower informed choices and improve targeted disposal. For authorities, the database would facilitate the SVHC monitoring to address regulatory actions, provide available information to support (waste) policy decisions and support enforcement. ${ }^{24}$

Certain specific mandatory requirements are, according to the ECHA justification, purely waste/WFD-driven, such as the article category and material category ("is important to identify certain relevant waste streams") and concentration range ("based on the most relevant concentration limits set out in Annex III of the Waste Framework Directive"). ${ }^{25}$

At the SCIP workshop on 12 November 2019, the NGO ClientEarth also provided support for the EC interpretation. It argues that the 'objective is key' for the interpretation of the SCIP scope. ${ }^{26}$ To this end it makes reference to a judgment of the General Court, which states: ${ }^{27}$

'59. According to settled case-law, in interpreting a provision of EU law, it is necessary to consider not only its wording but also the context in which it occurs and the objectives of the rules of which it is part $[\ldots]$

6o. In addition, since the textual and historical interpretations of a regulation, in particular of one of its provisions, do not permit its precise scope to be assessed, the legislation in question must be interpreted by reference to both its purpose and general structure [...].'

For the definition of the SCIP objectives, ClientEarth makes reference to Article 33 of REACH and explicitly to 'consumers' as recipients of the information, and to the development of non-toxic material cycles mentioned in recital 38 of Directive (EU) 2018/851. Furthermore, there is according to ClientEarth a need for precise information to effectively

24 See ECHA/de Bruijn, (n 20)

25 See ECHA, (n 11) 10.

26 See ClientEarth, 'SCIP database - a legal perspective' presentation at ECHA SCIP workshop on 12 November 2019 in Helsinki, available at $<$ https://echa.europa.eu/documents/10162/28534369/8_scip_en.pdf/7afdd32a-97f0c25d-6783-3b04abf73ad6> accessed 16 November 2019

27 CJEU, Judgment of 28 September 2016 - Case T-437/14.

28 See ClientEarth, (n 26). yield more information on SVHCs for public authorities to potentially impose restrictions, ensure adequate risk management including at the waste stage and empower consumers and business operators to make informed purchase choices (i.e. SVHC-free). ${ }^{28}$

\section{Legal Issues}

ECHA's detailed information requirements for the SCIP database and the underlying rationale raise a number of legal issues with regard to EU law that shall be analysed more closely in this section. First of all, the legal compliance of these requirements with WFD Art. 9 shall be investigated (1.). Second, the suggested implementation of WFD Art. 9(1)(i) and (2) will be checked against general principles of EU law (2.).

\section{Compliance with the Enacting Terms}

Issues with regard to the wording of WFD Art. 9(1)(i) and (2) shall be discussed first (a.), before turning to the objectives (b.).

\section{a. Wording}

A number of issues can be identified with regard to the legal text of WFD Art. 9(1)(i) and (2), which limits the mandatory scope of information requirements in several ways. At the outset, it should be recalled that SCIP notification and database are intrinsically linked to REACH Art. 33(1), based on the clear wording of WFD Art. 9(1)(i) 'provides the information pursuant to Article 33(1) of that Regulation' and Art. 9(2) 'establish a database for the data to be submitted to it pursuant to point (i) of paragraph 1'. This wording does not leave any doubt as to the referenced scope of SCIP notification and database, which is defined in REACH Art. 33(1) as 'sufficient information, available to the supplier, to allow safe use of the article including, as a minimum, the name of that substance.'

\section{i. Substance Name as REACH Art. 33 Minimum}

REACH Art. 33(1) is sufficiently clear in the sense that the minimum required information is the Candidate List substance name. By contrast, the minimum required information according to the EC and ECHA goes clearly beyond that (see above II.r.). Some 
of these requirements - such as article identifiers, production (or not) in the EU, number of linked articles, concentration ranges, material or mixture category - are not even mentioned in the latest ECHA Guidance on requirements for substances in articles (SiA Guidance), ${ }^{29}$ which provides recommendations for REACH Art. 33 communication. This Guidance also confirms repeatedly, referring to the legal text and the landmark judgment of the Court of Justice of the EU (CJEU) on the article definition under $\mathrm{REACH}^{30}$ that the substance name may be sufficient. ${ }^{31}$ Therefore, there is a clear mismatch between the ECHA detailed information requirements for SCIP, the legal text of REACH Art. 33(1) which applies via WFD Art. 9(1)(i) and (2), and also with respect to ECHA's SiA Guidance.

\section{ii. Flexible Scope of REACH Art. 33(1)}

Another concern arises from the flexible scope of REACH Art. 33(1) when going beyond the name of the substance, whereas ECHA's detailed information requirements in that regard are mandatory. ${ }^{32}$ According to ECHA's SiA Guidance, "[w]hat information is relevant to be communicated should however be assessed and decided on a case-by-case basis, in order to ensure that it fits the purpose of ensuring the safe use of articles. Type and detail of information on any one article may differ depending on who the recipient is." ${ }^{\prime 3}$ With this, the mandatory SCIP requirements virtually become part of and expand the scope of REACH Art. 33(1) communication (e.g. via contract requirements of the customer), whereas the logic of the law is just the other way around (REACH Art. 33(1) drives the SCIP provisions) and WFD Art. 9(1)(i) should be 'without prejudice to harmonised legal requirements concerning those materials and products laid down at Union level', i.e. chiefly REACH Art. 33.

It should also be remembered, in this context, that the scope of communication according to REACH Art. 33(1) rests on the premise that the information is 'available to the supplier'. This should be taken into account for SCIP notifications and the corresponding format.

\section{iii. The Silence of REACH on Complex Objects}

It also has to be taken into account that the REACH Regulation does not contain any provisions governing specifically the situation of a complex object containing more than one article. According to the CJEU, 'that legislative silence must be construed in the light of the principal objective pursued by the regulation, which is not to regulate all manufactured products, but to monitor the chemical substances present by themselves or in a mixture as well as, in certain cases, particularly those listed restrictively in Article 7 thereof, when they are contained in articles. ${ }^{34}$ Given the intrinsic link to REACH and its Article 33(1) in WFD Art. 9(1)(i) and (2) this should also apply to the SCIP notification and database. The detailed discussion by ECHA on complex objects and how to report information on those via SCIP notification and database (through 'linked articles', 'number of units' and various article identifiers) runs counter to this objective of substance regulation.

\section{iv. Restricted Access}

With regard to the scope of SCIP dissemination, WFD Art. 9(2) limits access to the database primarily to waste treatment operators ( $2^{\text {nd }}$ sentence). This primary focus reflects the scope of WFD. To consumers, ECHA shall provide access only 'upon request' $\left(3^{\text {rd }}\right.$ sentence). ${ }^{35}$ However, according to ECHA access shall also be granted to actors in the supply chain, NGOs and authorities. ${ }^{36}$ The SCIP database is planned to be public and hence accessible to everybody. Such public access to the SCIP database exceeds the wording and contradicts the structure of WFD Art. 9(2) with its tiered access levels. It also adds to the challenge of protecting confidential business information (CBI), which ECHA wants to ensure. ${ }^{37}$

29 ECHA, 'Guidance on requirements for substances in articles, June 2017, available at <https://echa.europa.eu/docu-

ments/10162/23036412/articles_en.pdf $>$ accessed 17 November 2019.

30 See CJEU, Judgment of 10 September 2015 - C-106/14, especially para 81 concluding based on the legal text of REACH Art 33 that the requirement is 'minimal in nature'.

31 ECHA, (n 29) 3, 26, 50.

32 It should be noted that part of the information is also voluntary, or picklists in the mandatory parts of the SCIP format allow the selection of generic values such as a concentration range between '> $0.1 \% \mathrm{w} / \mathrm{w}$ and $\leq 100 \% \mathrm{w} / \mathrm{w}$ '.

33 ECHA, (n 29) 50.

34 See CJEU, Judgment of 10 September 2015 - C-106/14, para 49.

35 Comparable to REACH Art 33(2).

36 See Section II.2.

$37 \mathrm{CBI}$ protection is another major issue with regard to the SCIP database. It cannot be further discussed within the scope of this article. For the latest ECHA plans to protect CBI, see Vieira Prazeres, How to make the data available and protect $\mathrm{CBI}$, presentation at ECHA SCIP workshop on 12 November 2019 in Helsinki, available at $<$ https://echa.europa.eu/docu-

ments/10162/28534369/6_scip_en.pdf/2a53e093-7445-1bd0-16 9c-63f781b61fe5> accessed 19 November 2019. 


\section{b. Objectives}

All parties in support of the detailed information requirements argue with the objectives of WFD Art. $9(1)(i)$ and $(2) \cdot{ }^{38}$ A key reference is made to recital 38 of Directive (EU) 2018/851. It is common ground that objectives of the law may play an important role for their interpretation. However, the analysis of objectives by these parties in the present case seems to lack precision for several reasons outlined below.

\section{i. Structure of Recital 38}

In its 'non-paper', the EC quotes the entire recital as a rationale, ${ }^{39}$ whereas ClientEarth highlights the development of non-toxic material cycles in the $2^{\text {nd }}$ sentence of recital 38. However, as shown above in Section I.2., recital 38 has a three-stage structure, consisting of the problem ( $1^{\text {st }}$ sentence), the objectives ( $2^{\text {nd }}$ sentence) and finally the means to achieve these objectives ( $3^{\text {rd }}$ sentence). The first means (to improve coherence among the law of the Union on waste, on chemicals and on products) is enacted in WFD Art. 9(1)(i) (through the link with REACH Art. 33(1)) and the second means (provide a role for ECHA to ensure that the information about the presence of substances of very high concern is available throughout the whole life cycle of products and materials, including at the waste stage) is enacted in WFD Art. 9(2).

It therefore remains unclear how the objectives mentioned in the $2^{\text {nd }}$ sentence would even have an added value when interpreting the scope of SCIP notification and database, not to speak about the other objectives brought forward by ECHA and ClientEarth (e.g. in relation to SVHC monitoring by authorities). The wordings of WFD Art. 9(1)(i) and (2) permit their precise scope to be determined. The flexibility of the

\footnotetext{
38 See Section II.2.

39 See EC, (n 7) 2.

40 See Section I.4.

41 CJEU, Judgment of 2 April 2009 - C-134/08, para 16; Judgment of 24 November 2005 - C-136/04, para 32, and the case-law cited.

42 Baratta, 'Complexity of EU law in the domestic implementing process' (July 2014) available at <https://ec.europa.eu/dgs/legal _service/seminars/20140703_baratta_speech.pdf $>$ accessed 14 November 2019

43 Klimas / Vaiciukaite, 'The law of recitals in European Community Legislation' (2008). Summary available at <http://ssrn.com/ abstract=1159604> accessed 2 December 2019.
}

scope of REACH Art. 33(1) (see above III.1.a.ii.) cannot be fixed through the teleological interpretation of WFD Art. 9(1)(i) and (2), even less so given the nature of REACH as a regulation (having general application and binding in its entirety) vs. WFD as a directive (which is to be transposed into national laws). ${ }^{40}$

\section{ii. Wording of Recital 38}

In relation to communication of information through to the waste stage, it should furthermore be noted that recital 38 only refers to (sufficient) information about the 'presence' of [...] substances. This is even narrower than REACH Art.33 ("sufficient information [...] to allow safe use of the article"). Therefore, the key argument brought forward by the EC that 'the information made available to those operators via the database has to be useful for the waste treatment phase of the article's lifecycle and enable the identification and effective treatment of waste containing SVHC' (see above II.2.), is not effective.

\section{iii. No Binding Legal Force of Recitals}

The CJEU has ruled that 'the preamble to a Community act has no binding legal force and cannot be validly relied on either as a ground for derogating from the actual provisions of the act in question or for interpreting those provisions in a manner clearly contrary to their wording. ${ }^{.41}$

This limitation is also echoed in other legal papers. The rationale of the case-law appears to be based on the principles of legal certainty and legitimate expectations. ${ }^{42}$ Klimas and Vaiciukaite convincingly concluded: 'Where both the recitals and the operative provisions are clear but inconsistent, the operative provision will control; corollary: recitals have no positive operation of their own. Where the recital is clear, it will control an ambiguous operative provision. This means that the operative provision will be interpreted in light of the recital. ${ }^{143}$

Both recital 38 and WFD Art 9(1)(i) and (2) are clear and consistent. Even if they were clear but inconsistent, WFD Art. 9(1)(i) and (2) - with the fundamental link to REACH Art. 33(1) - would prevail (control). The interpretation of WFD Art. 9(1)(i) cannot therefore legally go beyond the clear letter of the law. However, this appears to be the case with ECHA's detailed information requirements, as shown above in Section III.1.a. 


\section{General Principles of EU Law}

The issues raised by the implementation of WFD Art. 9(1)(i) and (2) with regard to general principles of EU law are not new - as similar questions have been or can be raised with respect to REACH Art. $33^{44}$ - however SCIP notification further adds to the burden for duty holders, and even more with ECHA's detailed information requirements. This section addresses the principles impossibilium nulla obligatio est (a.), proportionality (b.), equal treatment (c.), and legal certainty (d.).

\section{a. Impossibilium Nulla Obligatio Est}

The well-known legal principle impossibilium nulla obligatio est - no one can be obliged to do the impossible - can also be invoked in the European courts. ${ }^{45}$ It is becoming an issue if ECHA's detailed information requirements are turning into a 'mission impossible' for duty holders to fulfil given the sheer magnitude or the impossibility to obtain the required information from the supply chain. As of today, major challenges in this regard arise for importers of articles from outside EU, companies with a high turnover of different articles (products), where supply chains are changing on a frequent basis, for assemblers of complex objects ${ }^{46}$ relying on extensive global supply chains and supplier networks and/or where product details are confidential. ${ }^{47}$ Soon after adoption of the revised WFD in 2018, various industries have formed a joint position claiming that the 'ECHA proposal will not be workable for industry nor enforceable by authorities. ${ }^{48}$ While this position referred to the first ECHA 'draft scenario' released in October 2018, ${ }^{49}$ most of the arguments are still valid. ${ }^{50}$

\section{b. Proportionality}

According to the CJEU 'the principle of proportionality, which is enshrined in Article 5(4) TEU ${ }^{51}$ and which forms part of the general principles of EU law, requires, according to settled case-law, that measures adopted by the institutions do not exceed the limits of what is appropriate and necessary in order to attain the aim pursued; when there is a choice between several appropriate measures recourse must be had to the least onerous. ${ }^{152}$

Hence, the aims pursued and measures adopted (i.) have to be clarified before discussing appropri- ateness (ii.), necessity (iii.) and non-proportionality (iv.).

\section{i. Aims Pursued vs. Measures Adopted}

The measures adopted to look at are presently ECHA's detailed information requirements (Section II.1.).

The aims pursued by WFD Art. 9(1)(i) and (2), as described in recital 38 (2nd sentence), are 'to promote measures to reduce the content of hazardous substances in materials and products, including recycled materials, and to ensure that sufficient information about the presence of hazardous substances and especially substances of very high concern is communicated throughout the whole life cycle of products and materials." More specific aims as cited by the EC (usefulness for the waste treatment phase of the article's lifecycle and enable the identification and effective treatment of waste containing SVHC), ECHA (public database for everybody) and ClientEarth (information for public authorities, risk management, informed purchase choices) are not mentioned as such - even if they were desirable and not considered to be already duly addressed. Reading them into Directive (EU) 2018/851 for the purpose of justifying more detailed information requirements questions the rule of law and the legislative competence of the European Parliament and the Council to decide on matters of the Union policy on the environment as per TFEU Article 192(1).

44 Depending on the interpretation, in particular with regard to the level of reporting for complex objects.

45 See, for example, opinion of Advocate General Wathelet delivered on 11 April 2018 - Joined Cases C-622/16 P to C-624/16 P, para 105 et seqq.; CJEU, Judgment of 20 December 2017 C-664/15, para 96; Judgment 3 March 2016 - C-179/15, para 42.

46 See already Section II. 1.

47 See eg ASD-Eurospace, (n 7). Addendum 2 of the paper (6-7) elaborates on the implications of an assumed SCIP database inclusion for space products.

48 ACEA et al, 'Joint industry position paper regarding the Waste Framework Directive Database', available at <https://smeunited .eu/publications/joint-industry-position-paper-regarding-the-waste -framework-directive-database> accessed 18 November 2019.

49 ECHA, 'Draft scenario for the database on articles containing Candidate List substances', <https://echa.europa.eu/documents/ 10162/24198999/scenario en.pdf/3021c958-d5f3-e618-5e05 -be59b139822c > accessed 18 November 2019.

50 One key difference is though that the system of mandatory unique identifiers for articles generated by ECHA was abandoned. However, other mandatory identifiers are to be reported instead, see Section II. 1 .

51 Treaty of European Union.

52 See eg CJEU, Judgment of 20 September 2019 - T-636/17, para 205. 


\section{ii. Appropriateness}

ECHA's detailed information requirements may generally be appropriate to reduce the content of Candidate List substance in articles. The information about the presence of such substances in articles may alert the waste operators and thus help them to decide whether the waste they are dealing with is suitable for recycling or the production of secondary raw materials of high quality (see $1^{\text {st }}$ sentence of recital (38)). Of course, there is the challenge of finding corresponding database entries for the waste (stream) at hand. More specific information about the article(s) and the Candidate List substance(s) as defined in ECHA's detailed information requirements may help address this challenge and even increase usefulness of the information for the waste operator. Yet, the analysis cannot be exhaustive at this point, as no experience is available today. In any case, appropriateness is becoming an issue if ECHA's detailed information requirements are turning out to be impossible to fulfil (see also above i.).

\section{iii. Necessity}

As pointed out by the CJEU, when there is a choice between several appropriate measures, recourse must be had to the least onerous. Presently, a limited set of mandatory information requirements respecting the boundaries of REACH Art. 33(1) would be less onerous for duty holders, as they could draw on their current systems for REACH Art. 33(1) reporting without major adaptations. It may be less useful for waste operators, but is still appropriate to achieve the aims pursued (see above ii.) and the only option to be in compliance with the legal text (see Section III.1.). A certain 'erosion' of initial ECHA proposals can already be seen. ${ }^{53}$

\section{iv. Non-Proportionality}

Given the lack of prior impact and feasibility assessment (see Section I.3.), it is difficult to anticipate whether the costs and administrative burden are dis-

\footnotetext{
53 See (n 32).

54 Based on the feedback at the ECHA SCIP workshop on $12 \mathrm{No}$ vember 2019, see (n 2).

55 CJEU, Judgment of 10 September 2015 - C-106/14.

56 See ECHA / Uotila, (n 19).

57 See eg ACEA et al, (n 48).

58 Opinion 1/17 of the Court of 30 April 2019 ECLI:EU:C:2019:341, para 176 et seq and the case-law cited.
}

proportionate with regard to the added value of the database for waste operators and consumers. A significant cost and time impact for staff now tasked with SCIP compliance is already happening, while company IT systems are being reviewed for possible adaptation to enable system-to-system submissions to ECHA, new industry standards are being developed for SCIP-harmonized supply chain communication and contract requirements will need to be updated in order to obtain the needed additional data (if that is possible at all). ${ }^{54}$ These upfront investments by industry are hence already starting to show a measurable impact while the added value for waste operators and consumers is still an open question. SCIP notifications thus add another sizeable dimension to the existing burden, which just increased recently following the 'once an article, always an article' judgment of the CJEU of 10 September $2015 .{ }^{55}$ Non-proportionality of the costs is therefore a possible scenario.

\section{c. Equal Treatment}

One of ECHA's key underlying design considerations for the SCIP database is 'one size, fits all'. ${ }^{56}$ This means that the basic requirements are the same regardless of the industry sector and the type of product. Especially the producers of very complex objects had called vehemently for 'an approach that allows different, flexible and effective CE solutions tailored to the specific circumstances of each industry sector, depending on the complexity and durability of their products. ${ }^{57}$ This call could be supported by the principle of equal treatment, which requires that 'comparable situations must not be treated differently and different situations must not be treated in the same way, unless such treatment is objectively justified. ${ }^{158}$

WFD Art. 9(1)(i) and (2) do not differentiate between different types of article suppliers. However, the flexible scope of REACH Art. 33(1), to which these provisions refer, may result in a different extent of safe use communication depending on the product and customer, which should not be undermined by using a uniform approach. In this sense the principle of equal treatment warrants that ECHA respects the case-by-case nature of REACH Art. 33 communication.

The issue of equal treatment (i.e. to not treat different situations in the same way) could also become 
a question of validity of the enacting terms themselves. The 'once an article, always an article' judgment of the CJEU of 10 September $2015^{59}$ has made this question even more pertinent. It means that even the producers of the most complex assemblies are required to report Candidate List substances above 0.1 $\% \mathrm{w} / \mathrm{w}$ present in any smallest component to the customer. This interpretation has much added to the administrative burden for industries such as the aerospace and defence sector. ${ }^{60}$ A deeper analysis of this question (validity of WFD Art. 9(1)(i) and (2)) cannot be done within the scope of this article.

\section{d. Legal Certainty}

The principle of legal certainty requires, particularly, that rules of law be clear, precise and foreseeable in their effects, in particular where they may have adverse effects on individuals and undertakings. The principle of foreseeability is an integral part of the principle of legal certainty. ${ }^{61}$ As for the principle of equal treatment discussed previously, legal certainty is first and foremost a question of the validity of the legal provision or act, which cannot be analysed in depth within the scope of this article. For the SCIP database it appears less of a question because it is very descriptive, according to the ECHA plans. Current main uncertainties are the required level of reporting for multi-layer complex objects (see Section II.1.) and the definition of article for the purpose of SCIP notifications, i.e. when there is a different article or complex object requiring a distinct notification. ${ }^{62}$ It is expected, that ECHA, together with the EC and Member States, are still going to provide further clarifications in this regard. These are rather questions of interpretation.

\section{Conclusions and Outlook}

As of today, the SCIP implementation by ECHA has departed very much from the legal text. Its detailed information requirements to implement the new SCIP notification and database provisions in Article 9(1)(i) and (2) of the revised Waste Framework Directive raise serious concerns from a legal point of view.

The SCIP provisions are intrinsically linked to the supply chain communication obligation for EU article suppliers under REACH Art. 33(1), which contains clear limitations that should also drive the application of the WFD provisions. Instead, additional 'minimum' requirements are introduced by the EC and ECHA with regard to recital 38 of Directive (EU) 2018/851, thus re-interpreting REACH Art. 33(1) from a waste treatment point of view. Also, the envisaged public access to the SCIP database exceeds the wording and contradicts the structure of WFD Art. 9(2) with its tiered access levels.

In relation to recital 38 , it was shown that according to the CJEU recitals have no binding legal force and cannot be validly relied on either as a ground for derogating from the actual provisions of the act in question or for interpreting those provisions in a manner clearly contrary to their wording.

Furthermore, general principles of EU law may be concerned - that no one can be obliged to do the impossible, the wider principles of proportionality and equal treatment - especially with regard to (very) complex articles, which are common. The detailed discussion by ECHA on complex objects and how to report information on those via SCIP notification and database also runs counter to the objective of REACH as a substance regulation, which applies to SCIP requirements given their intrinsic link to REACH Article 33(1).

With its detailed requirements, ECHA has created a problematic fait accompli for the Member States, that are to transpose the revised WFD into national laws by 5 July 2020.

Overall, the implementation of the SCIP provisions, which were not part of the initial EC propos$\mathrm{al}$, suffers from the absence of a prior impact and feasibility assessment with due involvement of potential duty holders and waste treatment operators. Looking ahead, if WFD Art. 9(1)(i) and (2) are deemed to be insufficient, this has to be addressed by the colegislators following the ordinary legislative procedure of the TFEU as well as the principles of Better Law-Making.

59 CJEU, Judgment of 10 September 2015 - C-106/14.

60 See eg REACHLaw, 'Study on the impact of REACH and CLP European chemical regulations on the defence sector, Final Report' (16 December 2016) 61 et seqq, available at <https:// www.eda.europa.eu/docs/default-source/documents/eda-reach -study-final-report-2016-december-16-p.pdf> accessed 18 November 2019.

61 CJEU, Judgment of 11 May 2017 - T-115/15, para 135

62 The difference in SVHC content will be a main factor. 